\title{
Lesbos: uma nova tradução do poema de Charles Baudelaire, seguida de comentários
}

\section{Lesbos: a new translation of the poem by Charles Baudelaire, followed by commentary}

\author{
Rafael Augusto Duarte Freire* \\ Solange P. P. Carvalho**
}

Resumo: No presente artigo apresentamos nossa tradução integral do poema "Lesbos" de Charles Baudelaire. O comentário se divide em quatro partes, cujas funções são descrever e problematizar o poema e a tradução. Na seção Situação de "Lesbos" buscamos relacionar o poema com o horizonte mais amplo do projeto As flores do mal; na Baudelaire no Brasil, contextualizamos algumas importantes traduções prévias do poema; na Uma palavra sobre o Alexandrino, discutimos alguns desafios de tradução relativos à métrica; e em Considerações finais: liberdades, concluímos o artigo, focando em nossa intenção de valorizar a precisão formal e a coesão da sensualidade do poema.

\footnotetext{
* Mestrando pela Universidade de São Paulo.

** Pós-doutora pela Universidade de São Paulo.
} 
Palavras-chave: Baudelaire; Lesbos; tradução poética.

Abstract: In this essay we present our complete translation of the poem "Lesbos" by Charles Baudelaire. The commentary is divided in four parts whose function is to describe and discuss the poem and the translation. In the section "Situation of 'Lesbos'", we aim to relate the poem with the broader horizon of The flowers of evil as a whole; in "Baudelaire in Brazil", we contextualize some important previous translations; in "A word about the alexandrine", we go over a few translation challenges regarding metrics; and in "Final considerations: liberties" we wrap up the essay focusing on our intention to value formal precision and cohesion vis-à-vis the poem's sensuality.

Keywords: Baudelaire; Lesbos; poetic translation. 
Freire, R. A. D.; CARVALHO, S. P. P. - Lesbos: uma nova tradução do poema de Charles Baudelaire, seguida de comentários

\section{Lesbos - Charles Baudelaire}

Mère des jeux latins et des voluptés grecques, Lesbos, où les baisers, languissants ou joyeux, Chauds comme les soleils, frais comme les pastèques, Font l'ornement des nuits et des jours glorieux, 5 Mère des jeux latins et des voluptés grecques,

Lesbos, où les baisers sont comme les cascades Qui se jettent sans peur dans les gouffres sans fonds,

Et courent, sanglotant et gloussant par saccades, Orageux et secrets, fourmillants et profonds;

10 Lesbos, où les baisers sont comme les cascades!

Lesbos, où les Phrynés l'une l'autre s'attirent, Où jamais un soupir ne resta sans écho, À l'égal de Paphos les étoiles t'admirent, Et Vénus à bon droit peut jalouser Sapho!

15 Lesbos où les Phrynés l'une l'autre s'attirent,

Lesbos, terre des nuits chaudes et langoureuses, Qui font qu'à leurs miroirs, stérile volupté! Les filles aux yeux creux, de leur corps amoureuses, Caressent les fruits mûrs de leur nubilité;

20 Lesbos, terre des nuits chaudes et langoureuses,

Laisse du vieux Platon se froncer l'œil austère; Tu tires ton pardon de l'excès des baisers, Reine du doux empire, aimable et noble terre, Et des raffinements toujours inépuisés.

25 Laisse du vieux Platon se froncer l'œil austère.

Tu tires ton pardon de l'éternel martyre, Infligé sans relâche aux cœurs ambitieux, Qu'attire loin de nous le radieux sourire Entrevu vaguement au bord des autres cieux!

30 Tu tires ton pardon de l'éternel martyre!

Qui des Dieux osera, Lesbos, être ton juge Et condamner ton front pâli dans les travaux, Si ses balances d'or n'ont pesé le déluge De larmes qu'à la mer ont versé tes ruisseaux? 35 Qui des Dieux osera, Lesbos, être ton juge?

Que nous veulent les lois du juste et de l'injuste ?

Vierges au coeur sublime, honneur de l'archipel, Votre religion comme une autre est auguste, Et l'amour se rira de l'Enfer et du Ciel!

40 Que nous veulent les lois du juste et de l'injuste?

Car Lesbos entre tous m'a choisi sur la terre Pour chanter le secret de ses vierges en fleurs, Et je fus dès l'enfance admis au noir mystère Des rires effrénés mêlés aux sombres pleurs;

45 Car Lesbos entre tous m'a choisi sur la terre.

Et depuis lors je veille au sommet de Leucate, Comme une sentinelle à l'oeil perçant et sûr, Qui guette nuit et jour brick, tartane ou frégate, Dont les formes au loin frissonnent dans l'azur;

50 Et depuis lors je veille au sommet de Leucate,

Pour savoir si la mer est indulgente et bonne, Et parmi les sanglots dont le roc retentit Un soir ramènera vers Lesbos, qui pardonne, Le cadavre adoré de Sapho, qui partit

55 Pour savoir si la mer est indulgente et bonne!

De la mâle Sapho, l'amante et le poète, Plus belle que Vénus par ses mornes pâleurs! - L'œil d'azur est vaincu par l'œil noir que tachète Le cercle ténébreux tracé par les douleurs

60 De la mâle Sapho, l'amante et le poète!

- Plus belle que Vénus se dressant sur le monde Et versant les trésors de sa sérénité Et le rayonnement de sa jeunesse blonde Sur le vieil Océan de sa fille enchanté;

65 Plus belle que Vénus se dressant sur le monde!

- De Sapho qui mourut le jour de son blasphème, Quand, insultant le rite et le culte inventé, Elle fit son beau corps la pâture suprême D'un brutal dont l'orgueil punit l'impiété

70 De celle qui mourut le jour de son blasphème.

Et c'est depuis ce temps que Lesbos se lamente, $\mathrm{Et}$, malgré les honneurs que lui rend l'univers, S'enivre chaque nuit du cri de la tourmente Que poussent vers les cieux ses rivages déserts.

75 Et c'est depuis ce temps que Lesbos se lamente! 
Freire, R. A. D.; CARVALHO, S. P. P. - Lesbos: uma nova tradução do poema de Charles Baudelaire, seguida de comentários

\section{Lesbos - tradução de Rafael Freire}

Mãe da Roma floral e das volúpias gregas, Lesbos, onde sutis ou extravagantes beijos, Quentes que nem o sol, frescos que nem as mangas,

Das noites e manhãs famosas fazem jus,

5 Mãe da Roma floral e das volúpias gregas,

Lesbos: lá cafunés são como as cachoeiras Que caem sem temor em abismos infindos, E entre gemidos vão, vem, descendo ladeiras Como em meio a um tufão de segredos profundos;

10 Lesbos: lá cafunés são como as cachoeiras!

Lesbos, onde o vulcão desconhece o que é ira E em cujo oco sequer um ai ficou sem eco, Como Pafos, assim, o celeste te admira, E Vênus com razão inveja o charme sáfico!

15 Lesbos: onde o vulcão desconhece o que é ira,

Lesbos: lá as noites têm quentura e têm langor, 0 que faz a mulher, Oh estéril carícia!, Co' a moça no salão de ilusões de amor, Colhendo os frutos bons de tal adolescência;

20 Lesbos: lá as noites têm quentura e têm langor,

Deixa o velho Platão franzir a testa austera; Tu obténs teu perdão por excesso de beijos, Rainha cortesã em benévola era,

De sofisticação e requinte sobejos.

25 Deixa o velho Platão franzir a testa austera.

Tu adquires teu perdão do perpétuo martírio, Que sem interrupção se inflige aos mais ousados,

Que atrai longe de nós o riso rico e frio,

Entrevisto, pueril, à beira de outros mundos

30 Tu adquires teu perdão do perpétuo martírio!

Pois qual Deus ousará, Lesbos, ser teu algoz E te condenará o rosto rijo a obrar, Se co' a balança em vão pesaram a ampla foz De lágrimas que em rio induz maré no mar?

A que nos quer a lei dos justos ou injustos? Virgens de coração, sublime honra do Egeu, Vossa religião e credo são augustos,

E o amor tanto rirá seja do Inferno ou Céu!

$40 \quad$ A que nos quer a lei dos justos ou injustos?

Pois Lesbos logo a mim de tantos escolhera, P'ra o segredo cantar de suas virgens em flor. Fui desde a pequenez sabedor da arte obscura Do selvagem sorrir melado em densa dor;

45 Pois Lesbos logo a mim de tantos escolhera.

E velo desde então no topo do Leucate, Observando, sagaz, brigue, galé e fragata;

Dia e noite a varar, co' olho virado ao Leste,

Cujas formas no além tremem azul-violeta;

50 E velo desde então no topo do Leucate,

P'ra saber se a baía é complacente e boa, E meio ao soluçar que nas rochas ressoam Um dia qualquer trará, à Lesbos que perdoa, O cadáver amado e os que o amam lá irão

55 P'ra saber se a baía é complacente e boa!

Da Safo macho há: parte amante e poetiza, Que por sua palidez, é mais bela que Vênus! Cujos olhos azuis se rendem à negreza Do tenebroso anel traçado pelo ônus

60 Da Safo macho que há, parte amante e poetiza!

Dada ímpar maciez, vestida co' atitude, Verte ela o capital da serena beleza E acrescenta esplendor à negra juventude $E$ ao Oceano até, de uma moça bem formosa;

65 Dada ímpar maciez, vestida co' atitude,

De Safo que morreu no momento blasfemo Quando, insultando o altar da fé que se criou, De seu corpo ela fez enfim pasto supremo De um bruto, cujo orgulho, a impiedade puniu

70 De Safo que morreu no momento blasfemo.

Portanto desde então que Lesbos se lamenta, $\mathrm{E}$, malgrado os lauréis que the rende o universo, Se embebeda sem fim do grito da tormenta Que empurra à terra e aos céus seu litoral deserto.

75 Portanto desde então que Lesbos se lamenta! 
Freire, R. A. D.; CARVAlHo, S. P. P. - Lesbos: uma nova tradução do poema de Charles Baudelaire, seguida de comentários

\section{Situação de “Lesbos”}

"Lesbos" ocupa uma posição enigmática em sua relação com As flores do mal. Ele consegue figurar ao mesmo tempo como um dos poemas mais centrais e marginais, mais diretos e sinistros da obra. Evidencia-se sua centralidade, por exemplo, pelo fato de que quando As flores do mal se encontrava em fase de elaboração, Baudelaire cogitou chamar o volume de Les Lesbiennes ${ }^{1}$. Quanto à sua marginalidade, basta mencionar sua exclusão da segunda edição do livro a mando da justiça, que ademais condenou o autor por insulto aos bons modos (BAUdelaIRE 1985: 497). É difícil de imaginar que logo "Lesbos" fora censurado, junto com outros cinco poemas, em uma obra que comunica tamanha intensidade e variedade de supostos insultos como As flores do mal. Esta trata amiúde de temas como histeria, miséria, uso de drogas, sujeira, culto a forças demoníacas, etc., e os aborda de maneira tão escancarada quanto penetrante, com uma mistura de apologia e asco, de sarcasmo e integridade. Além da exclusão de seis poemas, o processo contra Baudelaire também lhe rendeu uma multa em dinheiro.

Se é possível conceber "Lesbos" como um poema especialmente maldito do poeta maldito, trata-se de um exemplo cabal de desencontro entre circunstâncias políticas e poéticas. De fato, quando olhamos para "Lesbos" pela lente literária, notamos a outra faceta que o faz especial. Nele, Baudelaire fixa, sem sua ironia característica, uma mensagem de beleza, suavidade e otimismo. A despeito de uma sensualidade estonteante, “Lesbos" se apresenta como um

\footnotetext{
1 "Este título não se explicaria senão pela presença deste poema e de outros dois que levam o título de 'Mulhares malditas', ou talvez, também, pelo segundo terceto de 'Sed non satiata', no qual o autor alude à anomalia sexual de Jeanne Duval." em nota do editor francês (ver BAUDELAIRE 1985: 497).
} 
FREIRE, R. A. D.; CARVALho, S. P. P. - Lesbos: uma nova tradução do poema de Charles Baudelaire, seguida de comentários

daqueles poucos poemas em que o spleen não tem vez. Referindo-se a uma estrofe do poema (v. 26-30), o editor francês escreve:

Examinando esses versos rigorosamente, parece que Baudelaire ainda não vê no safismo o apelo do abismo, a busca do infinito, mas o apelo de um mundo de beleza e de ternura puras. Assim se explicaria esse "sorriso radioso" que espanta em primeiro lugar. Sorriso esboçado, marca de um céu entrevisto. Diríamos sem imprecisão: marca do ideal. (BAUDELAIRE 1961: 436, tradução nossa) ${ }^{2}$

É interessante salientar que os apontamentos dos grandes críticos sobre a postura de Baudelaire n'As flores do mal concernentes à sexualidade parecem desfazer-se em pedaços se aplicados a “Lesbos". Auerbarch, por exemplo, escreve:

Em quase todo Baudelaire a relação entre amantes - ou mais precisamente entre os que estão ligados pela atração sexual - é representada como uma obsessão misturada ao ódio e ao desprezo, um vício que não perde nada de sua força atormentadora e degradante ao ser experimentado em plena (e indefesa) consciência. (AUERBACH 2007: 316)

\section{E Eliot:}

Um aforismo que se tem especialmente notado é o seguinte: $a$ voluptuosidade única e suprema do amor reside na certeza de fazer o mal. Isto quer dizer, penso, que Baudelaire compreendeu que o que distingue as relações do homem e da mulher da copulação dos animais é o conhecimento do Bem e do Mal [...] Tendo uma concepção romântica vaga, imperfeita, do Bem, foi pelo menos capaz de compreender que o acto sexual visto como mal é mais digno, menos enfadonho do que visto como o automatismo alegre, "vivificante", natural, do mundo moderno. (ELIOT 1992: 61)

\footnotetext{
2 "À prendre ces verses à la rigueur, il semble que Baudelaire ne voit pas encore dans le saphisme l'appel du gouffre, la recherche de l'infini, mais l'attirance d'un monde de beauté et de tendresse pures. Ainsi s'expliquerait ce « radieux sourire » qui étonne d'abord. Sourire esquissé, signe d'un ciel entrevu. On dirait sans inexactitude : signe de l'idéal."
} 
Freire, R. A. D.; CARVAlHo, S. P. P. - Lesbos: uma nova tradução do poema de Charles Baudelaire, seguida de comentários

"Lesbos" materializa por meio da sensualidade, expressa através da utopia lésbica, um exemplo de ideal, em contrapartida ao spleen reinante n'As flores do mal. Nesse poema o poeta francês faz uma concessão à sua visão mordaz, à qual apontam Eliot e Auerbach, da realidade. O editor francês corrobora:

[...] Baudelaire não era completamente avesso à interpretação idílica do safismo. É ela que explica seu poema "Lesbos", no qual dominam imagens de beijos, de voluptuosidade e de alegria. Ele já não pensava mais nisso quando escreveu Femmes damnées. (BAUDELAIRE 1961: 412, tradução nossa) $)^{3}$

Essa abertura para uma "interpretação idílica” já é em si rara n'As flores do mal ${ }^{4}$; adicione a isso a representação de uma sexualidade benigna, na qual não há ódio, desprezo, vício, e o mal não é o único elemento dignificante do amor - e ficará clara a magnitude do contraste desse poema. Talvez Eliot, Auerbach e outros não se refiram a "Lesbos" ao tratar do tema da sexualidade por ignorarem o poema ${ }^{5}$. Como consequência de sua condenação há mais de um século, até hoje os editores relegam "Lesbos" a uma posição de apêndice ao fim do livro.

O risco de acompanhar a oscilação do pêndulo muito para uma das extremidades é que percamos vista de onde ele veio. Não é exatamente justo dar

3 “'[...] Baudelaire n'était pas resté tout à fait fermé à [l’]interprétation idyllique du saphisme. C'est elle qui explique son poème "Lesbos » où dominent des images de baisers, de volupté et de joie. Il n'en est plus là quand il écrit Femmes damnées."

${ }^{4}$ Auerbach diz a próposito de As flores do mal: "É a obra do desespero e da amarga volúpia do desespero. Seu mundo é uma prisão." (AUERBACH, 2007: 325).

5 "Só nos resta concluir que todos os poemas de As flores do mal que lidam com temas eróticos estão impregnados da mesma desarmonia estridente e dolorosa que tentamos descrever [...] Quase em toda parte encontramos degradação e humilhação [...] Citações e análises são supérfluas - tudo isso é conhecido demais para os leitores de As flores do mal." (AUERBACH 2007: 320) 
Freire, R. A. D.; CARVALHo, S. P. P. - Lesbos: uma nova tradução do poema de Charles Baudelaire, seguida de comentários

a "Lesbos" ares de um poema banal. Afinal, trata-se de uma peça condenada do cáustico Baudelaire. Jamil Almansur Haddad, após reclamar para si o feito de ser o primeiro tradutor das pièces condamnées no Brasil, comenta:

Não se pode negar ter havido em nossa língua um certo sestro de querer dar um Baudelaire das famílias, a edição expurgada de As flores do mal constituída num alvo crítico a almejar. A sociedade que se escandalizou (e já adiantado o nosso século) com os arroubos sensuais de Gilka Machado, não iria suportar "Lesbos". (BAUDELAIRE 1958: 10)

Desde que essa observação foi feita, um novo século se desenvolve depressa. Deixaremos à discrição do leitor a decisão sobre se a sensualidade exuberante, embora não ferina, de "Lesbos" ainda tem ou não hoje o poder de chocar. Contudo, medindo pelo avanço que nossa sociedade tem experimentado em termos da promoção de direitos relacionados à diversidade e liberdade sexual, o tom de celebração com o qual Baudelaire tratou desse tema há 150 anos o qualifica como visionário. É nosso objetivo que esse aspecto do poema não se dissolva na tradução.

\section{Baudelaire no Brasil}

Henri Meschonnic sugere que a poética do traduzir é de certo modo a poética do retraduzir:

É sobre os grandes textos antigos que se acumulam as traduções. É neles que podemos confrontar uma invariante e suas variações. As razões delas, o como. O único terreno de experimentação da linguagem: onde as experiências podem recomeçar indefinidamente. 
Freire, R. A. D.; CARVAlHo, S. P. P. - Lesbos: uma nova tradução do poema de Charles Baudelaire, seguida de comentários

Lá, traduzir é uma poética experimental. (MESCHONNIC 1999: 11, tradução nossa) ${ }^{6}$

A obra de Baudelaire não se enquadra exatamente naquilo a que Meschonnic se refere quando fala de textes anciens. Porém, se não nos ativermos à esfera meramente cronológica, o fato de que o impacto d'As flores do mal nos últimos 150 anos tem sido tão imediato, universal e intenso, pode sim lhe conferir o status de clássico imemorial. Sobre a plateia de Baudelaire em nosso país, Álvaro Faleiros afirma:

Desde o artigo de Machado de Assis, de 1879, multiplicaram-se as reflexões e os mapeamentos da influência literária de Baudelaire no Brasil. Como assinala Antônio Cândido, nos anos de 1870 e começo dos de 1880, 'a presença de Baudelaire foi decisiva para definir os rumos da produção poética brasileira. E foram poucos os autores estrangeiros que alcançaram esse grau de influência na formação da literatura brasileira.' (FALEIROS 2001: 146)

A abundância de traduções do poeta francês atesta o caso. Haddad, o primeiro tradutor brasileiro a verter As flores do mal integralmente para o português, indica que a primeiríssima versão de um poema de Baudelaire surgiu em 1872 (BAUDELAIRE 1958: 40). Entre esta data e o próprio Haddad, encontramos o marco literário Flores das Flores do mal, de Guilherme de Almeida. Após Haddad aparecem pelo menos mais duas traduções integrais d'As flores do mal, a de Ivan Junqueira e a de Mário Laranjeira. O primeiro - tradutor em nosso país (ainda que de um único poema) de Baudelaire -, além de não possuir nenhuma versão em sua língua com a qual pudesse dialogar, teve de lidar com a tarefa de esboçar a imagem inicial do poeta no país. Mas para que se retratasse uma

\footnotetext{
6 “C'est sur les grands textes anciens que s'accumulent les traductions. C'est là qu'on peut confronter un invariant, et ses variations. Leur pourquoi, leur comment. Le seul terrain d'expérimentation du langage : où peuvent indéfiniment recommencer des expériences. Là, traduire est une poétique expérimentale."
} 
Freire, R. A. D.; CARVAlHo, S. P. P. - Lesbos: uma nova tradução do poema de Charles Baudelaire, seguida de comentários

imagem mais justa do alcance literário do poeta, foi necessário ampliar o escopo de poemas traduzidos. Guilherme de Almeida se propôs a isso, oferecendo 21 poesias de Baudelaire em português. Ao contrário de seu primeiro antecessor, Guilherme de Almeida necessitou lidar com a diacronia das suas traduções em relação à publicação e subsequente reconhecimento dos poemas franceses. A recepção construída de Baudelaire no Brasil por mais de 70 anos incluía a existência de várias traduções esparsas, e também a própria influência de Baudelaire na poesia nacional. A tradução d'As flores do mal em sua totalidade por Haddad abriu novos caminhos, acrescentando novas implicações. Em um projeto que inclui o volume inteiro, além de fazer sentido internamente, cada poema precisa também estar em harmonia com o todo.

Fazemos alguns apontamentos da tradição das traduções d'As flores do mal no Brasil, como modo de situar nosso próprio projeto. Ao contrário do que acontece com cada poema nos livros de Haddad, Junqueira e Laranjeira, para o nosso propósito não é essencial que "Lesbos" dialogue com os tantos outros poemas do volume. E em total oposição ao trabalho de 1872 , nossa tradução conta com uma ancorada tradição.

O que um olhar panorâmico da história nos revela sobre a posição das traduções de Baudelaire hoje? Faleiros escreve:

No caso de Baudelaire, trata-se de um poeta hoje conhecido da maioria dos leitores de poesia e, em língua portuguesa, boa parte desses ou já leu o texto de partida ou alguma tradução. Quem conhece as traduções de Baudelaire para o português sabe que, em sua grande maioria, por um excesso de zelo à forma, a maioria delas hiperdimensiona o caráter formal, transformando Baudelaire, frequentemente, num poeta parnasiano, ou quase. (FALEIROS 2001: 154)

Durante os muitos anos do intenso processo de recepção do poeta francês no país, à medida que certas conquistas foram consolidadas, outras lacunas se 
Freire, R. A. D.; CARVAlHo, S. P. P. - Lesbos: uma nova tradução do poema de Charles Baudelaire, seguida de comentários

abriram. Dá-se a entender que hoje uma tradução que evidencie o lado formal dos poemas estaria se propondo a fazer mais do mesmo. Faleiros indica como alternativa uma re-hierarquização das marcas poéticas de Baudelaire. Alinhandose a Alfonso Berardinelli, Faleiros sugere a necessidade de "retraduzir o horror" que leitores contemporâneos ao poeta devem ter sentido no contato inicial com os poemas, mas que se dissipou através das décadas. Faleiros comenta a propósito das reflexões do pensador italiano:

[...] em vez de valorizar a artificialidade em Baudelaire, elemento sem dúvida presente e importante, Berardinelli destaca o que chama de 'nudez anti-retórica', que se vincula a uma 'agudeza realista', até então desconhecida pela literatura. Estas seriam marcas da poética baudelairiana centrais para a compreensão de sua modernidade. [...] [0] destaque dado a 'originalidades estilísticas' e conquistas formais' não apenas seria redutor por não considerar a riqueza e diversidade das correntes, mas tampouco 'faz justiça ao sentido histórico e à situação expressa por essa poesia'. (FALEIROS 2001: 151-2)

Em sua retradução de Baudelaire, Faleiros usa a prosa ao invés do verso. 0 tradutor justifica essa escolha não apenas pela sua justeza na tarefa de enfatizar o aspecto prosaico dos poemas, mas no próprio fazer tradutório de Baudelaire - o qual, incidentalmente, elegeu a prosa para traduzir poemas de Poe.

Nossa abordagem pretende seguir o rumo que Faleiros propõe em termos de realçar o espanto no poema, porém através de um método contrário, um que nos leva de volta ao formalismo. Traduzimos "Lesbos" não apenas reativando o máximo das características formais imanentes que constituem o panorama comunicativo do poema, como ritmo, métrica e rima; mas buscamos inclusive valer-nos do tipo específico de alexandrino que Baudelaire emprega, o alexandrino com cesura. Esse aspecto rítmico soa pouco natural em português, o que em si nos ajuda, enquanto estratégia linguística, a imbuir o poema com um 
Freire, R. A. D.; CARVAlHo, S. P. P. - Lesbos: uma nova tradução do poema de Charles Baudelaire, seguida de comentários

certo desconforto. O próprio Faleiros admite que a "artificialidade" de Baudelaire é real e significativa. Em nossa opinião, o artifício em Baudelaire não é apenas considerável, mas de fato imperativo. Não é tão simples dissociar a poética do asco baudelairiana de seu verso típico.

O alexandrino insinuou sua importância para nós através de uma passagem esquecida do ensaio seminal "As flores do mal e o sublime", de Erich Auerbach (2007: 306-9). Observando as imagens criadas por Baudelaire - como, por exemplo, a comparação "do céu à tampa de uma panela" ou os "sinos que saltam furiosamente e urram para o céu" - Auerbach argumenta que Baudelaire brilha em sua capacidade de empregar termos baixos no contexto de um verso naturalmente nobre como o alexandrino, verso de Racine e Corneille. Mais que uma inserção bem sucedida, trata-se de uma eletrizante promoção de temas abjetos ou corriqueiros ao sublime. Quando abrimos mão do alexandrino, portanto, perdemos parte dessa dialética contraditória entre forma e conteúdo. Se assim o é; se não ao suposto hiperdimensionamento dos elementos formais dos poemas, a que se daria a tendência parnasiana diagnosticada por Faleiros nas traduções do trabalho de Baudelaire? Vimos que a tradução métrica equivalente (alexandrino por alexandrino) de Baudelaire no Brasil tende a resultar em poemas ao mesmo tempo mais parnasianos e menos perturbadores quando comparados com os poemas-fonte em francês. Gostaríamos de argumentar que o que causou o parnasianismo não foi exatamente o cuidado com o formal. De fato, como veremos, pensamos que os tradutores não se ativeram em demasia ao formal, pois que nem sequer ensaiaram a replicação em português da cesura, comum em Baudelaire e no verso alexandrino francês em geral. Como sugeriremos a seguir, o que causou o parnasianismo foram as escolhas léxico-vocabulares dos tradutores.

A busca por fidelidade de significados entre línguas - e não o zelo em relação à forma - foi o que fez com que os poemas de Baudelaire soassem 
Freire, R. A. D.; CARVAlHo, S. P. P. - Lesbos: uma nova tradução do poema de Charles Baudelaire, seguida de comentários

parnasianos. No presente projeto, tão importante quanto seguir o rigor rítmicosonoro é realçar o poder de causar o espanto do poema. Para isso pretendemos enfatizar o prosaico não por meio da forma, pois aqui nos aliamos a tradutores passados, mas por meio do léxico. Optamos por escolhas vocabulares que remetem às vezes ao mundo cultural brasileiro com sua mestiçagem, às vezes inclusive a imagens "inventadas", que vão além da demarcação semântica do próprio poema, mas que de um modo ou de outro são consistentes com nosso cuidando de manter Baudelaire, ainda hoje, tão belo quanto chocante.

\section{Uma palavra sobre o Alexandrino}

Décio Pignatari (1983: 32) ensina que há três tipos de alexandrino:

a) com acento nas $4^{\mathrm{a}}, 8^{\mathrm{a}}$ e $12^{\mathrm{a}}$ sílabas. É o mais comum e fácil; b) com acento na $6^{\mathrm{a}}$ e na $12^{\mathrm{a}}$, mas de tal forma que o acento na $6^{\mathrm{a}}$ recaia em palavra oxítona, dividindo o verso em duas partes iguais (hemistíquios); c) também com acento na $6^{\mathrm{a}}$, mas recaindo em palavra paroxítona terminada em vogal átona, que deve emendar (fazer elisão) numa vogal átona da palavra seguinte, para formar a $7^{a}$ sílaba. É o mais cheio de truques, o 'nobre dos nobres'. Exemplos tirados de Manuel Bandeira ilustram os três casos, pela ordem: a) 'Cita um sujeito que não leu, nunca, Alencar.' b) 'Fitando a vastidão magnífica do mar.' c) 'Sobre as águas, arfando, uma breve jangada.'

Em "Lesbos" Baudelaire recorre quase exclusivamente ao alexandrino do segundo tipo. Contudo, nas traduções brasileiras vigentes essa proporção não é mantida, havendo tantas ocorrências do primeiro tipo e do chamado nobre dos nobres quanto do segundo tipo. Foi através da tentativa de replicar a prevalência de versos enquadrados na segunda categoria em nossa própria tradução que 
FreiRe, R. A. D.; CARVAlHo, S. P. P. - Lesbos: uma nova tradução do poema de Charles Baudelaire, seguida de comentários

intuímos o motivo do desacordo: o problema tem a ver com o modo como a morfologia afeta a métrica. Não há proparoxítonas em francês; quanto às paroxítonas, elas só existem na escansão: "Toda a sílaba, muda ou sonora, conta na medida do verso"7 (DORCHAIN 44). Desse modo, uma palavra como parole, que em francês corrente possui somente duas sílabas, \ра.ьol\, contém três sílabas poéticas, pa-ro-le. 0 português contém uma quantidade pequena de proparoxítonas, um número maior de oxítonas e um ainda mais significativo de paroxítonas; já o francês conta preponderantemente com oxítonas. A contagem de sílabas mostrada acima só é válida em circunstâncias restritas como a métrica, e mesmo assim o poeta pode se valer de licença poética para ignorá-la, adequando-se assim às necessidades rítmicas do poema. A abundância de palavras em francês cuja tônica recai na última sílaba, por sua vez, facilita a realização do alexandrino do segundo tipo por oferecer mais opções de palavras com as quais concluir o primeiro dos dois hemistíquios. Portanto o verso alexandrino do tipo que vemos em "Lesbos" é mais natural à língua francesa do que à portuguesa. Embora seja esse o modo como explicamos a assimetria das traduções brasileiras em relação ao texto em francês, a intenção aqui não é fornecer evidências estatísticas. Apoiamo-nos na constatação prática: no processo de encontrar a palavra certa para concluir nitidamente o primeiro hemistíquio de cada um dos versos do poema, nos flagramos lançando mão de um emprego reincidente de certas classes de palavras, como verbos no futuro do presente e no infinitivo (vão [v. 8], ousará [v. 31]; cantar [v. 42], varar [v. 48]); substantivos ou adjetivos verbais (temor [v. 7], pequenez [v. 43], maciez [v. 8]) e outros substantivos que terminam em -ão (vulcão [v. 11], razão [v. 14], salão [v. 10], etc).

7 “Toute le syllabe, muette ou sonore, compte dans la mesure du vers". 
Freire, R. A. D.; CARVAlHo, S. P. P. - Lesbos: uma nova tradução do poema de Charles Baudelaire, seguida de comentários

Tomemos alguns versos das estrofes iniciais como exemplo. Na abertura do poema lê-se: "Mère des jeux latins et des voluptés grecques", que contém um primeiro hemistíquio com a sexta sílaba acentuada: Mè / re / des / jeux / la / tins //; e também um segundo hemistíquio de seis sílabas poéticas: et / des / vo / lup / tés / grec / (ques). Em termos de enunciado, temos em português: "Mãe dos jogos latinos e das volúpias gregas”. Assim, sobra uma sílaba poética e ficase longe de um metro adequado ao alexandrino; portanto é mister que o tradutor substitua algumas palavras do verso para adaptá-lo à realidade métrica do alexandrino. Jamil Almansur Haddad resolve o verso da seguinte maneira: "Mãe dos jogos do Lácio e da helénica orgia"; e Ivan Junqueira de modo semelhante: “Mãe dos jogos do Lácio e das gregas orgias". Desde já podemos constatar alguns elementos da transformação de Baudelaire em um "poeta parnasiano", como o sugeriu Faleiros. Os jogos latinos se transformam em jogos do Lácio, e as volúpias gregas, no caso de Haddad, em helênica orgia. Nossa versão, "Mãe da Roma floral e das volúpias gregas”, não apenas não abre mão dos hemistíquios (notem que tanto Haddad quanto Junqueira empregam o terceiro tipo alexandrino), isto é, sem cesura entre a sexta e sétima sílabas), mas busca evitar o tom rebuscado de jogos do Lácio que persiste ao decorrer das versões do poema propostas por esses dois grandes tradutores. Ainda assim, nota-se que em nossa versão também há concessões: é justo, por exemplo, traduzir jogos latinos em Roma floral?

Chegamos a essa solução através de um processo metonímico. Um dentre os vários tipos de jogos romanos (ludi romani), os jogos florais (ludi florales) celebravam a deusa Flora e eram marcados por orgias pastorais, prostitutas que lutavam nuas satirizando os gladiadores e outros tipos de libertinagem ${ }^{8}$. Além

\footnotetext{
8 Encyclopædia Romana: Floralia. Disponível em: <http://penelope.uchicago.edu/ grout/encyclopaedia_romana/calendar/floralia.html>. Último acesso em 3 de maio de 2016.
} 
Freire, R. A. D.; CARVAlho, S. P. P. - Lesbos: uma nova tradução do poema de Charles Baudelaire, seguida de comentários

disso, a palavra floral não é de todo inadequada dentro do universo sugestivo de sensualidade do poema. Mesmo com ressalvas, selecionamos o termo em grande parte por precisão métrica. 0 problema é que as palavras mãe, jogos e latinos, sem conectores, em si já somam as seis sílabas cabíveis no hemistíquio. Ainda que fosse possível contraí-las de algum modo, jogos e latinos são paroxítonas e, portanto, não devem concluir a primeira metade do verso, o que limita o campo de escolha. Por isso, é necessário buscar outras opções de vocabulário. Tentamos lazer: "Mãe do latino lazer", mas sobra uma sílaba. A palavra ócio é curta (começando com vogal, pode junto com a preposição do, por elisão, formar apenas duas sílabas poéticas), mas paroxítona. Diversão é oxítona mas trissílaba, ocupando sozinha metade do hemistíquio. Ainda mais problemáticas são divertimento, olímpicos... Uma alternativa seria retrabalhar o verso por completo. Por exemplo, pode-se fundir latinos e gregos em antigos, e por esta palavra no fim (notem que a rima não é alterada), livrando assim espaço com o qual possamos jogar. Algo como: “A mãe da diversão, das volúpias antigas, / É 'Lesbos'...” etc., seria possível. Sendo interessante definir somente uma escolha para que apareça na versão definitiva da tradução, preferimos enfim ficar com "Mãe da Roma floral". A seguir, transcrevemos a primeira estrofe nas três traduções mencionadas.

Mãe dos jogos do Lácio e da helênica orgia, Lesbos, teus beijos são langues ou voluptuosos, Resplendentes de sol, frios de melancia, Podem a noite ornar e os dias mais gloriosos;

Mãe dos jogos do Lácio e da helênica orgia,

Tradução Jamil Almansur Haddad

Mãe dos jogos do Lácio e das gregas orgias Lesbos, ilha onde os beijos, meigos e ditosos, Ardentes como sóis, frescos quais melancia, 
Freire, R. A. D.; CARVAlHo, S. P. P. - Lesbos: uma nova tradução do poema de Charles Baudelaire, seguida de comentários

Emolduram as noites e os dias gloriosos;

Mãe dos jogos do Lácio e das gregas orgias;

Tradução Ivan Junqueira

Mãe da Roma floral // e das volúpias gregas, $\quad 6+6$

Lesbos, onde sutis // ou extravagantes beijos, $6+6$

Quentes que nem o sol, // frescos que nem as mangas, $6+6$

Das noites e manhãs // famosas fazem jus, $6+6$

Mãe da Roma floral // e das volúpias gregas, $\quad 6+6$

Tradução Rafael Freire

Ainda sobre essa estrofe inicial, notem que nossa versão conclui o primeiro verso com gregas, o que permite uma rima com mangas do terceiro verso. Haddad e Junqueira rimam orgia e melancia, e orgias e melancia, respectivamente. Melancia é uma tradução denotativamente mais precisa de pastèques do que mangas o é, mas essa opção fica devendo em termos de rima nos dois casos. De todo modo, como sugerimos acima e reforçaremos mais tarde, o quadro léxico é o menos privilegiado na hierarquia de valores de nossa tradução. Forma e espanto é o que nosso projeto realça.

Tomaremos a estrofe seguinte como mais um exemplo do nosso modus operandi. Assim como traduzimos, para propósitos de rima, pastèques [melancias] por mangas, optamos por traduzir baisers por cafunés [v. 6]. Embora cafunés não traduza literalmente baisers, essa palavra serve a dois propósitos bem adequados dentro de nosso projeto tradutório: em primeiro lugar, ela é uma oxítona com a qual se terminar o hemistíquio; e em segundo lugar, ela qualifica uma noção de sensualidade e remete, ao mesmo tempo, à presença da cultura africana, por via etimológica, no Brasil. Similarmente, vertemos a palavra saccades do francês em ladeiras [v. 8]. A ideia foi evocar uma termo vívido no imaginário brasileiro: ladeiras de Ouro Preto, ladeiras do carnaval de Olinda; canções populares, por exemplo, "Lá vem o Brasil descendo a ladeira", e assim 
Freire, R. A. D.; CARVALHo, S. P. P. - Lesbos: uma nova tradução do poema de Charles Baudelaire, seguida de comentários

por diante. A seguir explicaremos um pouco mais o que guiou essas tomadas de liberdade denotativa. Comparemos por ora a segunda estrofe nas três versões:

Lesbos, onde em cascata escorrem sempre os beijos, Lançados sem pavor nos abismos mais fundos,

E correm soluçando em partidos arquejos, Secretos, a fremir, tormentosos, profundos;

Lesbos, onde em cascata escorrem sempre os beijos!

Tradução de Jamil Almansur Haddad

Lesbos, ilha onde os beijos são como as cascatas, Que desabam sem medo em pélagos profundos

E correm, soluçando, em meio às colunatas, Secretos e febris, copiosos e infecundos; Lesbos, ilha onde os beijos são como as cascatas!

Tradução de Ivan Junqueira

Lesbos: lá cafunés // são como as cachoeiras, $\quad 6+6$

Que descem sem temor // em abismos infindos, $\quad 6+6$

E entre gemidos vão, // vem, descendo ladeiras $\quad 6+6$

Como em meio a um tufão // de segredos profundos, $6+6$

Lesbos: lá cafunés // são como as cachoeiras! $\quad 6+6$

Tradução de Rafael Freire

Aqui, novamente, no contexto do projeto ao qual nos propomos, termos como pélagos, colunatas ou partidos arquejos não nos são satisfatórios. Aqui também observamos a prevalência de metros sem cesura, com exceção dos segundo e quarto versos de Haddad e do quarto de Junqueira.

\section{Considerações finais: liberdades}


Freire, R. A. D.; CARVALHo, S. P. P. - Lesbos: uma nova tradução do poema de Charles Baudelaire, seguida de comentários

Elaborando sua noção de tradução poética enquanto recriação, Haroldo de Campos escreve:

[P]ara nós tradução de textos criativos será sempre recriação, ou criação paralela, autônoma porém recíproca. Quanto mais inçado de dificuldades esse texto, mais recriável, mais sedutor enquanto possibilidade aberta de recriação. Numa tradução dessa natureza, não se traduz apenas o significado, traduz-se o próprio signo, ou seja, sua fisicalidade, sua materialidade mesma [...] O significado, o parâmetro semântico, será apenas e tão somente a baliza demarcatória do lugar da empresa recriadora. Está-se, pois no avesso da chamada tradução literal. (CAMPOS 2013: 5)

Como já ficou claro, dirigidos entre outras coisas pelo objetivo acima, tomamos liberdades na tradução. Transcrevamos agora o pensamento de outro grande crítico para embasá-las. Discorrendo sobre o conflito entre simbolismo e realismo a propósito de um dos poemas de Baudelaire, Auerbach afirma:

Não tem importância alguma saber se ele de fato ouviu sinos tocando num dia chuvoso. O todo é uma visão do desespero, a exposição dos detalhes é puramente simbólica. Os dados têm tão pouca importância que os símbolos podem ser deslocados sem que haja perda [...] (AUERBACH 2007: 308)

Não seria legítimo aplicar esse padrão à tradução? Trazendo a discussão precisamente para esse âmbito, Laranjeira traz à tona certo trecho de uma carta que Manuel Bandeira escreveu a Alphonsus Guimarães Filho:

Mas aqui peço para the dar uma lição: sempre que você quiser traduzir um poema, faça um estudo preliminar no sentido de apurar o que é essencial nele e o que foi introduzido por exigência técnica, sobretudo de rima e métrica. [...] As rosas podem ser substituídas por lírios. Não importa que seja esta ou aquela flor, e era preciso uma flor de nome masculino por causa da rima [...] (LARANJEIRA 1993: 108) 
Freire, R. A. D.; CARVAlHo, S. P. P. - Lesbos: uma nova tradução do poema de Charles Baudelaire, seguida de comentários

Isso é completamente válido, a não ser que, como Bandeira bem apontou, o nome da flor seja essencial. 0 corvo de Poe não pode ser uma garça ou um pombo. Cada caso é um caso.

Retornando a "Lesbos", gostaríamos de salientar rapidamente alguns momentos de nossa tradução em que fugimos, ou não, da demarcação semântica exposta no original. As Frineias [v. 11], por exemplo, caíram; assim como o dilúvio [v. 33]. Já as menções à cidade de Pafos [v.13] e ao Leucate [v. 46] permaneceram, bem como aquelas a Platão [v. 21/25]. As melancias [v. 3] viraram mangas, os beijos [v. 6] viraram cafunés e as sacadas [v. 8] viraram ladeiras, como discutimos anteriormente. A juventude loira [v. 63] virou negra, o que representa outro caso da tentativa de fazer Baudelaire falar à nossa realidade brasileira.

Para nos reter em apenas um dos casos ora mencionados, o mais extremo dentre eles, explicitemos que ao invés da imagem das Frineias, inserimos a imagem de um vulcão sereno, a qual não figura no poema fonte. Uma leitora do manuscrito deste artigo insinuou que o vulcão é uma imagem assaz masculina para entrar em "Lesbos". Para contestar essa noção, invocamos a agudeza feminina de um dos Love Poems (XI) de Adrienne Rich (2015, tradução nossa), onde ela expressa:

Cada pico é uma cratera. Essa é a lei dos vulcões, fazendo deles eterna e visivelmente fêmea. Nada de altura sem profundidade, sem um núcleo ardente, embora nossas solas de palha destrocem na lava endurecida. ${ }^{9}$

\footnotetext{
9 "Every peak is a crater. This is the law of volcanos, making them eternally and visibly female. No height without depth, without a burning core, though our straw soles shred on the hardened lava."
} 
Freire, R. A. D.; CARVALHo, S. P. P. - Lesbos: uma nova tradução do poema de Charles Baudelaire, seguida de comentários

Além disso, a figura que o verso posterior propõe, "Où jamais un soupir ne resta sans écho", funciona bem demais dentro da calma concavidade de um vulcão para ser negligenciada. Podemos igualmente salientar que a imagem de um vulcão, normalmente associada à violência das erupções - pensemos em Pompeia, por exemplo -, também pode levar os leitores a estabelecer uma relação entre o abalo sísmico provocado pela movimentação do magma sob a crosta terrestre e o abalo que o poema causou na sociedade na época de sua publicação.

Cabe fazer duas ressalvas para justificar as liberdades. Em primeiro lugar, nosso projeto já dialoga com uma tradição, reconhecendo a existência de uma poesia fonte em francês e de traduções prévias, e necessitando delas para um bom funcionamento no polissistema brasileiro contemporâneo. Em segundo lugar, nenhuma nova tradução tira o espaço já ocupado pelo texto fonte no cânone, assim como não podemos deixar de lado a influência exercida por Baudelaire em nossa literatura ao longo dos últimos 150 anos. Como esperamos ter deixado claro, nossa intenção é dialogar com essa rica tradição, revelando alguma faceta nova do poema, um novo jeito de lê-lo - jamais apresentar a leitura absoluta. Finalmente, visando maximizar o papel da subjetividade na tradução, nosso projeto tem por objetivo não esconder, e até enfatizar, nossa brasileiridade e nordesteza, e o tempo em que vivemos, no poema traduzido.

\section{Referências bibliográficas}


Freire, R. A. D.; CARVALHo, S. P. P. - Lesbos: uma nova tradução do poema de Charles Baudelaire, seguida de comentários

AuerbaCH, Eric. As flores do mal e o sublime. In: AuerbaCH, Eric. Ensaios de literatura ocidental. Tradução de Samuel Titan Jr. e José Marcos Mariani de Macedo. São Paulo: Editora 34, 2007.

BaUdelaire, Charles. As flôres do mal. Tradução Jamil Almansur Haddad. São Paulo: Garnier, 1958.

- As flores do mal. Tradução Ivan Junqueira. Nova Fronteira, Rio de Janeiro: 1985.

. Les fleurs du mal. Paris : Garnier, 1961.

CAMPOS, Haroldo de. Transcriação. São Paulo: Perspectiva, 2013.

DorChaIN, Auguste. L'art des vers. Paris : Librairie des Annales, s/d.

ELIOT, T. S. Ensaios escolhidos. Lisboa: Cotovia, 1992.

FALEIROS, Álvaro. As flores do mal sem medida: por uma retradução de Charles Baudelaire. São Paulo, 2001. Disponível em: <http://www.abralic.org.br/revista/2011/19/126/download>.

Laranjeira, Mário. Poética da tradução: do sentido à significância. São Paulo: Edusp, 1993.

Meschonnic, Henri. Poétique du traduire. Paris : Verdier, 1999.

PIgnatari, Décio. Comunicação Poética. São Paulo: Editora Moraes, 1983.

$\mathrm{RICH}$, Adrienne. The Dream of a Common Language. In: Twenty-One Love Poems.

Genius.com, 2015. Último acesso em 10 de julho de 2015. URL: http://genius.com/Adrienne-rich-twenty-one-love-poems-annotated.

Data de submissão: 04/05/2016

Data de aprovação: 01/02/2017 